CHROM. 3963

\title{
A technique for sample application in preparative-layer chromatography
}

A major problem in preparative-layer chromatography (PLC) is the application of a relatively large amount (ca. $0.5-\mathrm{I} .0 \mathrm{~g}$ ) of sample to a conventional $200 \times 200 \times 2$ $\mathrm{mm}$ layer of adsorbent. Various methods have been devised ${ }^{1-6}$ for this purpose.

A simple and efficient method for the application of large amounts of sample for PLC was developed in our laboratory. This method essentially involves the following steps: (I) preparing a narrow channel in the adsorbent layer; (2) mixing the removed adsorbent with the sample; and (3) placing this sample-adsorbent mixture into the channel. This procedure requires the use of a template such as that shown in Fig. I.

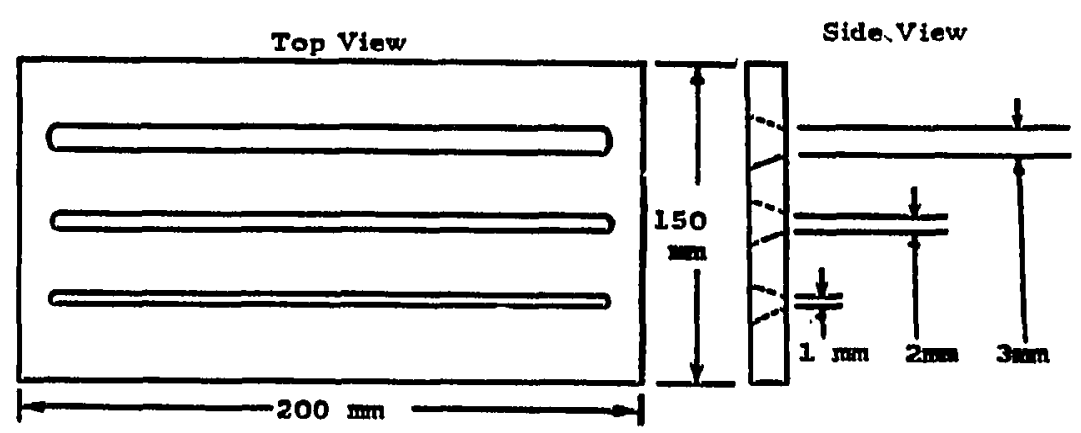

Fig. I. Template for sample application in preparative-layer chromatography. Macle from $\mathrm{I} / 8 \mathrm{in}$. harclencel aluminum.

The following experiment demonstrates the use of this technique. The template shown in Fig. I was placed on top of a commercial ${ }^{*} 200 \times 200 \times 2 \mathrm{~mm}$ plate of silica gel containing organic binder so that the $3-\mathrm{mm}$ groove coincided with the desired line of sample application. A 3-mm channel was cut completely through the adsorbent with several passes of a razor blade, using the edges of the template groove as a guide. The channel was made $I .5 \mathrm{~cm}$ from the bottom edge of the chromatography plate and extended to within $\mathrm{I} \mathrm{cm}$ of each side of the plate. The loosened adsorbent was removed by means of a vacuum apparatus similar to that described by RITTER AND MEYER ${ }^{1}$. The adsorbent thus removed was gently tamped into a graduated cylinder and its volume noted. A solution of $0.5 \mathrm{~g}$ of a $\mathrm{I}: \mathrm{I}$ mixture of fluorene and fluorenone in a small amount of benzene was placed on a watch glass and was mixed with $0.5 \mathrm{ml}$ of the adsorbent previously removed from the plate. This mixture was ground and stirred until it became dry and powdery. Enough fresh adsorbent was then added to make a total volume equal to that of the adsorbent originally removed from the plate. After being thoroughly mixed, this material was distributed in the channel in the plate as evenly as possible with a spatula, using the template as a guide. This mixture was then gently tamped with the edge of a piece of glass. The template was carefully removed, and any sample remaining outside the channel was gently brushed into the channel and tamped. The plate was either developed directly, or the material in the channel was first moistened with a small amount of hexane and then was carefully pressed

\footnotetext{
* DeSaga-Brinkman Instruments, Westbury, New York.
} 
down with the piece of glass. This wetting technique was especially helpfull when larger amounts of sample were chromatographed because it prevented the formation of cracks in the channel as the sample moved up the plate during development. A single vertical development of the plate in benzene-hexane ( $I: I)$ gave excellent separation of the hydrocarbon from the ketone. In the same manner, using a 5-mm channel and two developments, a I.0-g sample of the same mixture was resolved with remarkably good separation. This method of sample application has been used routinely in our laboratory with excellent results, even with unbound layers of adsorbent. Smaller amounts (200 $\mathrm{mg}$ or less) of sample were applied in a I-mm channel.

This procedure of sample application in PLC offers several advantages. The apparatus is simple and inexpensive. The sample is uniformly distributed throughout the zone of application in all dimensions. Also, it is not necessary to apply a solution, of the sample, as the sample (solid or liquid) can be powdered with adsorbent and then placed on the plate. Finally, large amounts of sample can be confined to a narrow zone, a difficult and time-consuming operation with a sample solution.

Department of Chemistry, The University of Michigan, Ann Arbor, Mich. 48 ro4 (U.S.A.)

Thomas D. Weaver*

DAVID M. TEEgARDEN

I F. J. Ritter AND G. M. MEYER, Nature, I93 (I962) 94 I.

2 J. P. Connolly, P. J. Flanagan, R. O. Dorchat and J. B. Thomson, J. Chromatog., i 5 (ig64) Io5.

3 C. G. Honegger, Helv. Cham. Acta, 45 (1962) I 410.

4 L. B. FArMER, J. Chromatog., I6 (1964) $4 \mathrm{I2}$.

5 J. H. Fessler AND H. Galley, Nature, 201 (1964) 1056.

6 M. Motrier and M. Potterat, Anal. Chim. Acta, I3 (1955) 5 r.

Received January 23rd, I969

"Present address: Du Pont de Nemours \& Co., Inc., Photo Products Department, Rochester, N.Y. $I_{4} 6 r_{3}$, U.S.A. 